\title{
Linopirdine-Supplemented Resuscitation Fluids Reduce Mortality in a Model of Ischemia-Reperfusion Injury Induced Acute Respiratory Distress Syndrome
}

\author{
Favin S. BABU ${ }^{1}$, Matthias MAJETSCHAK ${ }^{2,3}$
}

${ }^{1}$ Department of Surgery, Loyola University Chicago, Stritch School of Medicine, Maywood, USA, ${ }^{2}$ Departments of Surgery and ${ }^{3}$ Molecular Pharmacology and Physiology, University of South Florida, Morsani College of Medicine, Tampa, USA

Received March 3, 2021

Accepted April 29, 2021

Epub Ahead of Print June 2, 2021

\section{Summary}

Previously, we demonstrated that supplementation of resuscitation fluids with the Kv7 voltage-activated potassium channel inhibitor linopirdine reduces fluid resuscitation requirements and stabilizes hemodynamics in various rat models of hemorrhagic shock. To further evaluate the therapeutic potential of linopirdine, we tested the effects of linopirdinesupplemented resuscitation fluids in a rat model of ischemiareperfusion injury-induced acute respiratory distress syndrome (ARDS). Ventilated rats underwent unilateral lung ischemia from $\mathrm{t}=$ 0-75 $\mathrm{min}$, followed by lung reperfusion and fluid resuscitation to a mean arterial blood pressure of $60 \mathrm{mmHg}$ with normal saline (NS, $\mathrm{n}=9$ ) or NS supplemented with $50 \mu \mathrm{g} / \mathrm{ml}$ linopridine (NS-L), $\mathrm{n}=7$ ) until $\mathrm{t}=360 \mathrm{~min}$. As compared with NS, fluid resuscitation with NS-L stabilized blood pressure and reduced fluid requirements by $40 \%$ ( $p<0.05$ vs. NS at $t=240-360 \mathrm{~min}$ ). While NS-L did not affect ARDS development, it reduced mortality from $66 \%$ with NS to $14 \%$ with NS-L ( $p=0.03$, hazard ratio 0.14 ; $95 \%$ confidence interval of the hazard ratio: 0.03-0.65). Median survival time was 240 min with NS and >360 min with NS-L. As compared with NS treated animals that survived the observation period $(n=3)$, however, plasma lactate and creatinine concentrations at $t=360$ min were higher with NS-L $(n=6$; $p<0.05$ ). Our findings extend therapeutic potential of NS-L from hypovolemic/hemorrhagic shock to hemodynamic instability under normovolemic conditions during organ ischemiareperfusion injury. Possible adverse effects of NS-L, such as impairment of renal function and/or organ hypoperfusion, require further evaluation in long-term pre-clinical models.

\section{Key words}

Kv7 voltage-activated potassium channel inhibitor • Fluid resuscitation • Survival • Hemodynamics

\section{Corresponding author}

Matthias Majetschak, Department of Surgery, Morsani College of Medicine, University of South Florida, 12901 Bruce B Downs Blvd., MDC 3127, Tampa, FL 33612, USA. E-mail: majetschak@usf.edu

Kv7 voltage-activated potassium channels are important regulators of the membrane potential in excitable cells (Haick and Byron 2016, Mackie and Byron 2008, Miceli et al. 2008, Wulff et al. 2009). Kv7 channels display an activation threshold near the resting membrane potential and generate outwardly rectifying potassium currents, which stabilize resting membrane potential and suppress cell excitability (Haick and Byron 2016). Drug development has as yet focused on the use of $\mathrm{Kv} 7$ channels as drug targets in neurological diseases and Kv7 channel activators have been approved by the U. S. Food and Drug Administration for the treatment of pain and partial-onset seizures, respectively (Faulkner and Burke 2013, Harish et al. 2012). Kv7 channels, however, have also been recognized as important regulators of vascular smooth muscle function (Byron and Brueggemann 2018, Haick and Byron 2016, Mackie and Byron 2008). Evidence suggests that drugs targeting Kv7 channels might be useful to regulate 
vascular reactivity and blood pressure in various pathological conditions (Byron and Brueggemann 2018, Haick and Byron 2016, Stott et al. 2014). Recently, we showed that supplementation of resuscitation fluids with the Kv7 channel inhibitor linopirdine reduces fluid resuscitation requirements and stabilizes hemodynamics in various rat models of hypovolemic-hemorrhagic shock (Nassoiy et al. 2018, Nassoiy et al. 2017). The effects of linopirdine-supplemented resuscitation fluids in normovolemic injury models, however, are unknown. Thus, we employed a model of unilateral lung ischemiareperfusion injury-induced acute respiratory distress syndrome (ARDS) to further explore therapeutic potential of linopirdine-supplemented resuscitation fluids. This model suffices key criteria of the Berlin definition of ARDS, i.e. to result in a ratio of arterial oxygen partial pressure to fractional inspired oxygen $(\mathrm{P} / \mathrm{F})<300 \mathrm{mmHg}$ under positive end-expiratory pressure $\geq 5 \mathrm{cmH}_{2} \mathrm{O}$, and leads to pronounced hemodynamic instability and fluid requirements under normovolemic conditions (Babu et al. 2020). All procedures were approved by the Institutional Animal Care and Use Committee of Loyola University Chicago. Male Sprague-Dawley rats (300-350 g; Harlan, Indianapolis, IN, USA) were anesthetized (isoflurane inhalation), oro-tracheally intubated with a 16-gauge EXEL disposable safelet angiocatheter (EXELINT International, Los Angeles, CA, USA) and mechanically ventilated with a SomnoSuite small animal anesthesia system (Kent Scientific Corporation, Torrington, CT, USA). Animals were ventilated with a pressurecontrolled ventilator mode with an initial positive end expiratory pressure (PEEP) of $2 \mathrm{mmHg}$, a fraction of inspired oxygen $\left(\mathrm{FiO}_{2}\right)$ of 1.0 and anesthetized with isoflurane at $2.5 \%$. Tidal volumes were titrated to maintain normal $\mathrm{PaCO}_{2}(35-45 \mathrm{mmHg})$. The femoral artery was cannulated with 24-gauge $\mathrm{BD}$ angiocath shielded IV catheters (Becton, Dickinson and Company, Franklin Lakes, NJ, USA) to allow for monitoring of arterial blood pressure and blood withdrawal, and the femoral vein was cannulated with 1.5 -french tubing for fluid and drug administration. Animals underwent a right lateral thoracotomy, and a suture was placed around the hilum of the right lung. The animals were systemically heparinized with 150 units $/ \mathrm{kg}$ of heparin through the femoral vein and the suture was tied around the hilum of the right lung, occluding the pulmonary artery, vein, and right main stem bronchus $(\mathrm{t}=0 \mathrm{~min})$. At $\mathrm{t}=75 \mathrm{~min}$ the suture was removed, animals were ventilated with $\mathrm{FiO}_{2}$ 1.0 , and PEEP $5 \mathrm{mmHg}$. Immediately thereafter, animals were resuscitated to a mean arterial blood pressure (MAP) of $60 \mathrm{mmHg}$ with either normal saline (NS, N=9) or $50 \mu \mathrm{g} / \mathrm{ml}$ linopridine in NS (NS-L, $\mathrm{N}=7$ ). The concentration of linopirdine was selected based on our previous studies (Nassoiy et al. 2017, 2018). To prevent acute fluid overload, NS and NS-L infusion was limited to a maximal infusion rate of $1 \mathrm{ml} / \mathrm{min}$ irrespective of the MAP target during resuscitation. A sigh breath was administered every 15 breaths for the first $5 \mathrm{~min}$ following resuscitation and then every 90 breaths until $\mathrm{t}=360 \mathrm{~min}$ to fully expand the post ischemic lung. Hemodynamics were continuously monitored with the surgivet invasive blood pressure monitor (MedElectronics, Beltsville, MD, USA) and blood pressures values were recorded continuously throughout the experiment. Arterial blood gases and routine laboratory parameters were collected in regular intervals throughout the experiment. At $\mathrm{t}=360 \mathrm{~min}$, animals were euthanized (5\% isoflurane, bilateral pneumothorax, arterial exsanguination). All experiments were performed randomized and blinded. Arterial blood gases, electrolytes, creatinine, lactate, hematocrit and hemoglobin were analyzed using the Element point of care veterinary blood gas, electrolyte and critical care analyzer (Cuattro Veterinary USA, Loveland, CO, USA). Complete blood counts were analyzed using the Hematrue hematology analyzer (Cuattro Veterinary). Data are presented as mean \pm standard error. Data were analyzed by 2 -way analysis of variance (ANOVA) with Dunnett's multiple comparisons test or with the unpaired Student's t-test, as appropriate, and survival was analyzed with the Log-rank test using the GraphPad Prism program (GraphPad Software). A two-tailed $\mathrm{p}<0.05$ was considered significant.

There were no differences in any of the physiological parameters between groups at baseline (Fig. 1 and 2). All animals could be resuscitated to a MAP of $60 \mathrm{mmHg}$ (Fig. 1A). While diastolic blood pressures were indistinguishable between groups, systolic blood pressures in animals resuscitated with NS-L were significantly higher between $\mathrm{t}=140-320 \mathrm{~min}$, as compared with the systolic blood pressures of animals resuscitated with NS (Fig. 1B/C). While animals resuscitated with NS required $640 \pm 113 \mathrm{ml} / \mathrm{kg}$ of fluid to achieve the target MAP during the resuscitation period, resuscitation with NS-L reduced fluid requirements by $40 \%$ to $387 \pm$ $59 \mathrm{ml} / \mathrm{kg}(\mathrm{p}<0.05$ vs NS, Fig. 1D). The finding that hematocrit values were indistinguishable between groups suggests that intravascular volume was comparable 
(Fig. 1E). Animals fulfilled $\mathrm{P} / \mathrm{F}$ criteria for ARDS $(\mathrm{P} / \mathrm{F}<300 \mathrm{mmHg})$ at $\mathrm{t}=120 \mathrm{~min}$ until the end of the observation period, irrespective of the resuscitation fluid (Fig. 1F). Similarly, arterial partial pressure of carbon dioxide and $\mathrm{pH}$ were indistinguishable between groups at all time points (Fig. 1G/H). While lactate levels normalized in animals that were resuscitated with NS and survived until $\mathrm{t}=360 \mathrm{~min}$, lactate levels remained elevated with NS-L resuscitation. Although these differences were not statistically significant when analyzed by 2-way ANOVA/Dunnett's post-hoc test, lactate levels at the end of the experiments were significantly higher with NS-L, as compared with NS resuscitation, when analyzed with unpaired Student's t-test (NS: $2.4 \pm 0.05 \mathrm{mmol} / \mathrm{l}(\mathrm{n}=3)$; NS-L: $9.2 \pm 1.9 \mathrm{mmol} / \mathrm{l} \quad(\mathrm{n}=6) ; \mathrm{p}=0.047$; Fig. 1I). Furthermore, creatinine and potassium concentrations continuously increased with NS-L resuscitation, but remained constant with NS resuscitation (Fig. 2A/B).
Sodium concentrations showed a tendency toward lower values and were significantly lower at $\mathrm{t}=150$ and $240 \mathrm{~min}$ with NS-L resuscitation, as compared with animals resuscitated with NS (Fig. 2C). Remarkably, however, NS-L resuscitation reduced mortality from $66 \%$ with NS resuscitation to $14 \%(\mathrm{p}=0.03$; Hazard ratio NS-L/NS = 0.14 (95\% confidence interval: 0.03-0.65); Fig. 2D). Median survival time was $240 \mathrm{~min}$ and $>360 \mathrm{~min}$ with NS and NS-L resuscitation, respectively. Because $\mathrm{P} / \mathrm{F}$ ratios and hematocrit values were comparable between the groups, hypoxemia and fluid overloadinduced right heart failure unlikely account for the observed survival difference. All animals that died during the observation period, however, showed a rapid loss of blood pressure within a few minutes. Thus, it is reasonable to assume that the fluid-sparing and blood pressure stabilizing effects of NS-L resuscitation reduced mortality by preventing acute circulatory failure. This
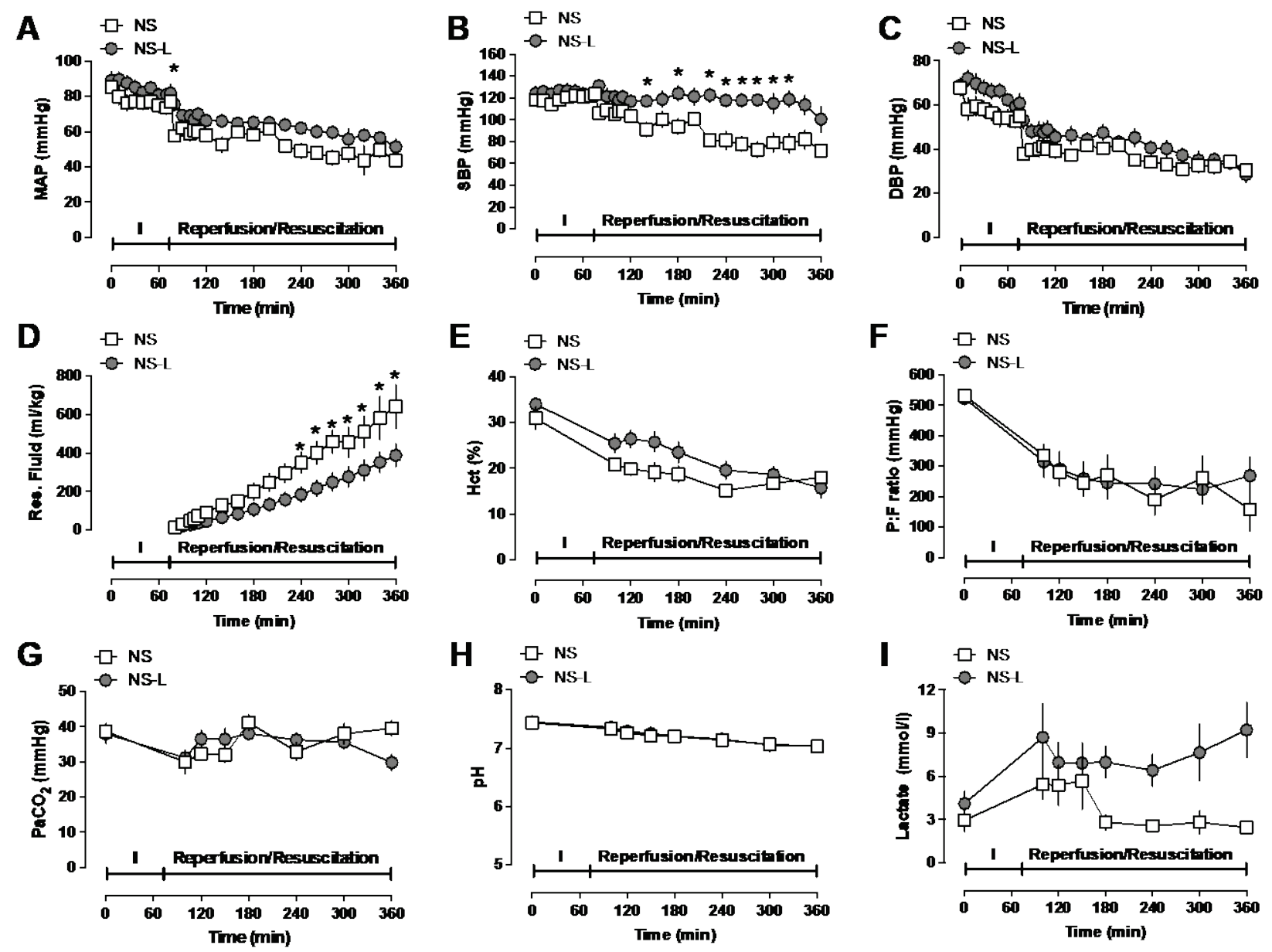

Fig. 1. Animals underwent $75 \mathrm{~min}$ of right lung ischemia (I) followed by lung reperfusion and fluid resuscitation to a MAP of $60 \mathrm{mmHg}$ until $\mathrm{t}=360 \mathrm{~min}$. Animals were resuscitated with NS (open squares, $\mathrm{n}=9$ ) or with NS supplemented with $50 \mu \mathrm{g} / \mathrm{ml}(\mathrm{grey} \mathrm{circles,} \mathrm{n}=7$ ) of linopirdine (NS-L). Data are mean \pm SE. *: p<0.05 vs NS alone (two-way ANOVA/ Dunnett's multiple comparisons test). A. MAP $(\mathrm{mmHg})$. B. SBP: Systolic blood pressure $(\mathrm{mmHg})$. C. DBP: Diastolic blood pressure $(\mathrm{mmHg})$. D. Res. Fluid $(\mathrm{ml} / \mathrm{kg})$ : resuscitation fluid requirements to achieve target MAP. E. Hct: Hematocrit values (\%). F. P/F ratio: ratio of arterial oxygen partial pressure to fractional inspired oxygen $(\mathrm{mmHg})$. G. $\mathrm{PaCO}_{2}$ : partial pressure of carbon dioxide in arterial blood $(\mathrm{mmHg})$. H. pH. I. Blood lactate levels (mmol/l). 

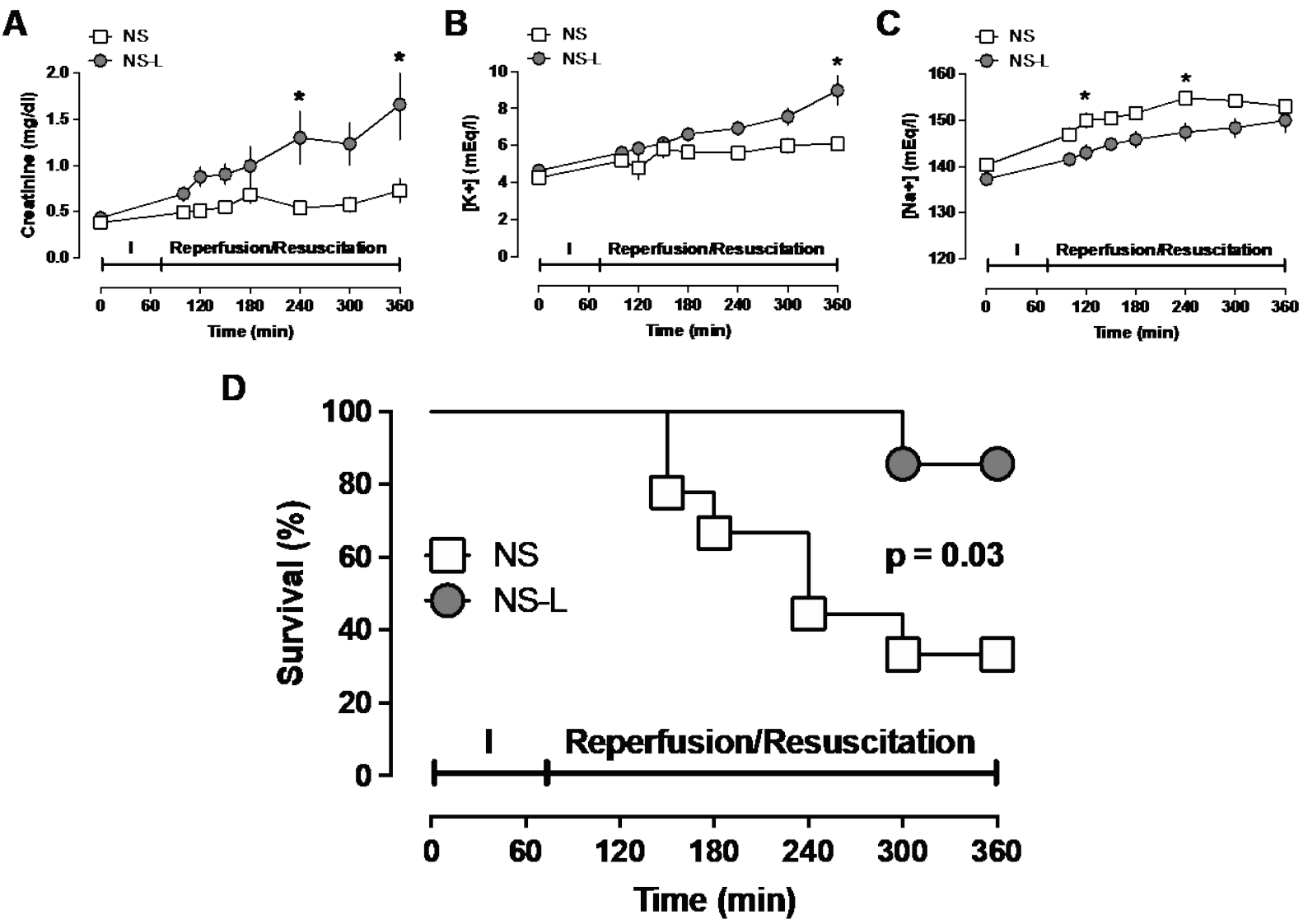

Fig. 2. Animals underwent $75 \mathrm{~min}$ of right lung ischemia (I) followed by lung reperfusion and fluid resuscitation to a $\mathrm{MAP}$ of $60 \mathrm{mmHg}$ until $\mathrm{t}=360 \mathrm{~min}$. Animals were resuscitated with NS (open squares, $\mathrm{n}=9$ ) or with NS supplemented with $50 \mu \mathrm{g} / \mathrm{mL}$ (grey circles, $\mathrm{n}=7$ ) of linopirdine (NS-L). Data are mean \pm SE. $*$ : $p<0.05$ vs NS alone (two-way ANOVA/ Dunnett's multiple comparisons test). A. Blood creatinine concentrations $(\mathrm{mg} / \mathrm{dl})$. B. $\mathrm{K}^{+}$: Blood potassium concentrations $(\mathrm{mEq} / \mathrm{l})$. C. $\mathrm{Na}^{+}$: Blood sodium concentrations (mEq/l). D. Kaplan Meier survival curve. Survival was analyzed with the Log-rank test.

would be consistent with the clinical observations that circulatory failure is among the most common causes of mortality in patients with ARDS (Pierrakos and Vincent 2012). In combination with the previous observation that Kv7 channel blockade constricts the renal vasculature and reduces renal blood flow in rats (Salomonsson et al. 2015), our observations on creatinine, electrolyte and lactate levels may indicate that the beneficial effects of NS-L are achieved at the expense of impaired renal function and tissue hypoperfusion. Although some of these observations could also be explained, at least partially, by dilutional effects due to significant differences in fluid requirements between groups, impairment of kidney function and tissue hypoperfusion should be carefully evaluated as possible adverse effects of linopirdine in future pre-clinical studies. A limitation of the present study is the relatively small number of animals in each group, which mandates caution in the interpretation of our findings on mortality. It should be noted, however, that such effects were unexpected, and the study was primarily designed to assess effects of
NS-L on fluid resuscitation requirements. Nevertheless, given the significant effects of NS-L on survival time and fluid requirements in the present study, the possible side effect profile could be clinically manageable and mitigated through improvement of the dosing regimen of NS-L. In conclusion, this study further expands the therapeutic potential of linopirdine to significant fluidsparing properties that are associated with prolonged survival in a normovolemic ischemia-reperfusion injury model and identifies a potential side-effect profile of NS-L. Long term resuscitation studies, beyond the 360 min observation period of the present study, appear necessary to further define benefits and risks associated with NS-L treatment.

\section{Conflict of Interest}

There is no conflict of interest.

\section{Acknowledgements}

Research reported in this publication was supported by the National Institute of General Medical Sciences of the 
National Institutes of Health under Awards necessarily represent the official views of the National R01GM139811 and T32GM008750. The content is Institutes of Health.

solely the responsibility of the authors and does not

\section{References}

BABU FS, LIANG X, ENTEN GA, DESANTIS AJ, VOLKMAN BF, GAO X, MAJETSCHAK M: Natural and engineered chemokine (C-X-C motif) receptor 4 agonists prevent acute respiratory distress syndrome after lung ischemia-reperfusion injury and hemorrhage. Sci Rep 10: 11359, 2020. https://doi.org/10.1038/s41598-020$\underline{68425-0}$

BYRON KL, BRUEGGEMANN LI: Kv7 potassium channels as signal transduction intermediates in the control of microvascular tone. Microcirculation 25, 2018. https://doi.org/10.1111/micc.12419

FAULKNER MA, BURKE RA: Safety profile of two novel antiepileptic agents approved for the treatment of refractory partial seizures: ezogabine (retigabine) and perampanel. Expert Opin Drug Saf 12: 847-855, 2013. https://doi.org/10.1517/14740338.2013.823399

HAICK JM, BYRON KL: Novel treatment strategies for smooth muscle disorders: Targeting Kv7 potassium channels. Pharmacol Ther 2016. https://doi.org/10.1016/j.pharmthera.2016.05.002

HARISH S, BHUVANA K, BENGALORKAR GM, KUMAR T: Flupirtine: Clinical pharmacology. J Anaesthesiol Clin Pharmacol 28: 172-177, 2012. https://doi.org/10.4103/0970-9185.94833

MACKIE AR, BYRON KL: Cardiovascular KCNQ (Kv7) potassium channels: physiological regulators and new targets for therapeutic intervention. Mol Pharmacol 74: 1171-1179, 2008. https://doi.org/10.1124/mol.108.049825

MICELI F, SOLDOVIERI MV, MARTIRE M, TAGLIALATELA M: Molecular pharmacology and therapeutic potential of neuronal Kv7-modulating drugs. Curr Opin Pharmacol 8: 65-74, 2008. https://doi.org/10.1016/j.coph.2007.10.003

NASSOIY SP, BABU FS, LAPORTE HM, BYRON KL, MAJETSCHAK M: Effects of the Kv7 voltage-activated potassium channel inhibitor linopirdine in rat models of haemorrhagic shock. Clin Exp Pharmacol Physiol 2018. https://doi.org/10.1111/1440-1681.12958

NASSOIY SP, BYRON KL, MAJETSCHAK M: Kv7 voltage-activated potassium channel inhibitors reduce fluid resuscitation requirements after hemorrhagic shock in rats. J Biomed Sci 24: 8, 2017. https://doi.org/10.1186/s12929-017-0316-1

PIERRAKOS C, VINCENT JL: The changing pattern of acute respiratory distress syndrome over time: a comparison of two periods. Eur Respir J 40: 589-595, 2012. https://doi.org/10.1183/09031936.00130511

SALOMONSSON M, BRASEN JC, BRAUNSTEIN TH, HAGELQVIST P, HOLSTEIN-RATHLOU NH, SORENSEN CM: K(V)7.4 channels participate in the control of rodent renal vascular resting tone. Acta Physiol (Oxf) 214: 402-414, 2015. https://doi.org/10.1111/apha.12525

STOTT JB, JEPPS TA, GREENWOOD IA: K(V)7 potassium channels: a new therapeutic target in smooth muscle disorders. Drug Discov Today 19: 413-424, 2014. https://doi.org/10.1016/j.drudis.2013.12.003

WULFF H, CASTLE NA, PARDO LA: Voltage-gated potassium channels as therapeutic targets. Nat Rev Drug Discov 8: 982-1001, 2009. https://doi.org/10.1038/nrd2983 